\title{
Evidências bibliométricas do distanciamento entre acadêmicos e praticantes de marketing
}

Prioridades diferentes de praticantes e acadêmicos de Marketing levam ao seu distanciamento. Acadêmicos normalmente focam em publicações nos periódicos mais prestigiosos. Praticantes de Marketing costumam não se ocupar com publicações, concentrando-se na solução dos problemas profissionais. Este artigo responde à dúvida se títulos de livros e artigos científicos de Marketing evidenciam esse distanciamento entre academia e prática. Foi realizado um estudo bibliométrico, coletando-se por meio de web-scraping 351 títulos de livros sobre Consumer Behavior e 293 sobre Marketing Research, e também, 252 títulos de artigos do Journal of Marketing, 336 do Journal of Consumer Research e 332 do Journal of Marketing Research. Utilizando a Análise de Conteúdo foram criadas 8 categorias de análise. A análise do Teste Qui-quadrado de Pearson $\left(\chi^{2}\right)$ indicou que existe uma associação significativa entre as categorias de análise propostas (8) e o tipo de publicação $\left(2\right.$, Livros e Artigos Científicos), $\chi^{2}(7, N=5.112)=518,274, p=, 000, V$ de Cramer $=, 318$. A partir dos Resíduos Ajustados foi possível afirmar que 7 das 8 categorias mostraram associação entre os tipos de publicação, com destaque para as categorias Conceitos e Instruções, sendo a primeira preponderante em artigos científicos e a segunda em livros. Os resultados evidenciam o distanciamento entre acadêmicos e profissionais de Marketing. Sugere-se que se promova a interlocução entre as partes, para reduzir o distanciamento e beneficiar ambos os domínios.

Palavras-chave: Teoria de Marketing; Prática de Marketing; Divulgação Científica; Mercado Editorial.

\section{Bibliometric evidences of a divide between marketing academics and practitioners}

\begin{abstract}
Marketing practitioners and academics have different priorities and this causes a divide between them. Academics often seek publishing in prestigious journals. Practitioners often do not know these publications, focusing in professional challenges. This paper aims to answer whether titles of books and scientific articles are evidence of the gap between academia and practice in the area of marketing. It was then performed a bibliometric research, which started by collecting through web-scraping 351 book titles on Consumer Behavior and 293 on Marketing Research, as well as 252 article titles from the Journal of Marketing, 336 from the Journal of Consumer Research and 332 of the Journal of Marketing Research. Using Content Analysis, 8 categories were created in which the terms used in the titles were coded. The analysis of Pearson's $\chi 2$ indicated that there is a significant association between proposed categories ( 8 ) and the type of publication (2, Books and Scientific Articles), $\chi 2(7, N=5,112)=518,274, p=, 000$, Cramer's $V=, 318$. From the Adjusted Residues, it was possible to state that 7 of the 8 categories showed an association between the types of publication, with emphasis on the categories Concepts and Instructions, the first being predominant in scientific articles and the second in books. The results are evidence of the gap between academia and practice in the area of Marketing. As a result, a dialogue between the parties should be encouraged, in order to reduce the distance and benefit both academics and practitioners.
\end{abstract}

Keywords: Marketing Theory; Marketing Practice; Science Divulgation; Editorial Market.

Topic: Marketing e Estratégias Mercadológicas

Reviewed anonymously in the process of blind peer.
Received: 09/01/2021

Approved: 21/03/2021
Fábio Roberto Borges (iD)

Universidade Federal de Minas Gerais, Brasil

http://lattes.cnpq.br/3654000716624220

http://orcid.org/0000-0003-2588-4730

fabioborges@ufmg.br

Ricardo Teixeira Veiga (iD)

Universidade Federal de Minas Gerais, Brasil

http://lattes.cnpq.br/2160652000585374

http://orcid.org/0000-0001-5467-0972

ricardo.necc@gmail.com

Matheus Resende Rocha

Universidade Federal de Minas Gerais, Brasil

http://lattes.cnpq.br/2428987097481591

http://orcid.org/0000-0001-7595-5678

counas22@ufmg.br
Referencing this:

BORGES, F. R. F.; VEIGA, R. T.; ROCHA, M. R.. Evidências bibliométricas do distanciamento entre acadêmicos e praticantes de marketing. Revista Brasileira de Administração Científica, v.12, n.1, p.52-64, 2021. DOI: http://doi.org/10.6008/CBPC2179-684X.2021.001.0005 


\section{INTRODUÇÃO}

Resultado de condições econômicas e sociais de uma sociedade de consumo em efervescência no início do século $\mathrm{XX}$, o estudo acadêmico especializado de Marketing surgiu como alternativa à teoria econômica convencional para explicar a dinâmica dos consumidores e das ofertas de mercado (LIMA et al., 2014). Tal perspectiva é capaz de revelar o otimismo de uma orientação normativa, comum em ciências gerenciais, mas incompatível com uma visão positiva da ciência (VEIGA, 2018). Assim, desde o princípio o Marketing despertou nos praticantes do campo o interesse pela possibilidade de encontrar evidências científicas que poderiam levar suas empresas a um desempenho superior à média.

Por conta dessa relação da disciplina com a prática, é possível se considerar difícil a resposta à questão de qual veio primeiro na área do Marketing, se foram as melhores práticas de mercado ou as evidências consistentes sobre o comportamento do consumidor e do mercado (KAUPPINEN-RÄISÄNEN et al., 2015). No entanto, ao se pensar num cenário de pouca convivência entre acadêmicos e praticantes, essa pergunta pode se tornar aos poucos irrelevante, à medida que as duas áreas atuem cada vez mais independentes.

De maneira geral, alguns podem acreditar que a academia é por sua natureza conservadora e existe uma morosidade para a aceitação de novos conceitos (FISK et al., 1993), oriundos da experiência bemsucedida. É possível que essa característica venha da necessidade de prudência de só legitimar resultados com base em estudos científicos metodologicamente consistentes.

No entanto, no cenário atual de hipercompetitividade e exposição constante imposta pelas novas práticas na internet, os praticantes da área de Marketing se sentem constantemente impelidos a agir e reagir com grande velocidade, experimentando novos arranjos e soluções. Dispondo de um volume cada vez maior de dados sobre consumidores e seu comportamento, os profissionais de Marketing passaram a desenvolver seus próprios modelos e criar "teorias em atividade", provenientes de estratégias e suposições contextualmente orientadas (REPSOLD et al., 2018).

Contudo, por adotarem constantemente melhores práticas de mercado, dada a urgência de experimentar novas estratégias, os praticantes de Marketing recorrem muitas vezes à literatura de mais fácil acesso - livros de negócios, disponíveis até mesmo em bancas de aeroportos. Essa literatura de negócios, principalmente na área de Marketing, tende a trazer reembalar ou "requentar" ideias conhecidas, apresentando-as como grandes insights revolucionários (SOUTHGATE, 2006). Essas novas roupagens promovem, no máximo, uma mudança incremental nas rotinas do campo, a partir do hype (expectativa muitas vezes exagerada) vinculada às mais recentes buzzwords (palavras e conceitos da moda). Porém, tais modismos podem validar decisões gerenciais, fazendo os executivos se sentirem mais competentes e atualizados. Esse comportamento e cenário, comuns também em outras áreas profissionais, facilitam a proliferação do charlatanismo e pseudociência (VEIGA, 2018).

Observe-se, entretanto, que praticantes não recorrem usualmente à literatura acadêmica especializada, por diversos motivos, tais como desconhecimento, dificuldade de acesso, incompreensão da 
linguagem científica e falta de tempo para refletir sobre a transposição dos achados acadêmicos para sua prática (BRENNAN, 2004).

Na esfera acadêmica de Marketing, temos um mecanismo de socialização de pesquisadores que são, assim como em outras áreas, educados na illusio (relativa ao quanto é interessante participar do jogo social) de uma corrida pela produtividade em termos de publicações científicas (DOSTALER et al., 2013). Nesse contexto, o prestígio - e também a retribuição material do trabalho - desses acadêmicos estão muito mais atrelados à produtividade, medida por publicações em journals prestigiosos, do que no impacto dos trabalhos nas atividades profissionais e diálogo com o campo.

Com essas diferenças de domínios e prioridades, é possível que a cisão de acadêmicos e praticantes de Marketing venha se intensificando, conforme suas linguagens e objetivos se tornam aparentemente incompatíveis. Para verificar empiricamente se este distanciamento retrata fidedignamente o relacionamento entre prática e academia na área de Marketing, este artigo visa a apresentar os resultados de um estudo bibliométrico que analisa os títulos, temas de interesse e termos utilizados por autores que publicam em journals e por autores que objetivam alcançar os praticantes através de livros, comparando suas diferentes abordagens e finalidades.

\section{REVISÃO TEÓRICA}

\section{Acadêmicos e praticantes no campo do marketing}

$\mathrm{Na}$ área da saúde os profissionais recorrem diretamente às fontes científicas para orientar as suas práticas, porém, no campo do Marketing raramente os praticantes recorrem ao conhecimento gerado pelos acadêmicos (SOUTHGATE, 2006). Este parece ser um consenso não somente entre os praticantes, mas também entre os acadêmicos que sentem que não possuem meios pelos quais seus textos podem chegar diretamente ao campo prático da disciplina (BRENNAN, 2004).

No geral os praticantes tendem a reclamar que os acadêmicos não fazem esforço suficiente para que esse distanciamento diminua, porque não abordam temas diretamente relevantes para resolver os problemas gerenciais e nem tornam seus achados mais disponíveis ou mais palatáveis (BRENNAN, 2004). Parece ser o caso, inclusive, que resultados de pesquisa considerados pelos acadêmicos como de maior valor e qualidade em contrapartida possam ser avaliados pelos praticantes como sendo os de menor interesse (BRENNAN, 2004).

A pesquisa científica em Marketing não deve ser pautada necessariamente pelas urgências do mercado profissional, embora obviamente deva ter relevância prática. A pesquisa científica busca entender relações entre respostas, impactos e dinâmicas do comportamento de consumidores, ações empresariais e da relação de mercado entre organizações e sociedades. No entanto, a prioridade científica de compreensão aprofundada dos fenômenos não justifica a cisão entre teoria e prática, pois boas teorias e conceitos úteis instruem e aumentam a produtividade do trabalho profissional. Por isso, a incomunicabilidade e afastamento entre acadêmicos e praticantes são deploráveis e devem ser superados. 
Interessante notar, no entanto, que frequentemente os acadêmicos da área de Marketing, pesquisadores e professores universitários, são responsáveis pela formação de praticantes, nos cursos de graduação e pós-graduação. A dificuldade de compreensão das melhores práticas e falta de experiência de campo dos acadêmicos fundamentam queixas dos estudantes de que a dimensão técnica aplicada deixa a desejar, por exemplo, na falta de exemplos práticos e discussão de casos relevantes professores e alunos (DOSTALER et al., 2013). Uma possível solução para essa deficiência é a oferta de uma educação em Marketing baseada em evidências, focada em desenvolver a capacidade crítica dos estudantes, que possam encontrar nas evidências aplicações práticas para contextos específicos de negócios (KAUPPINEN-RÄISÄNEN et al., 2015).

Outra razão para o distanciamento entre praticantes e acadêmicos é a cultura do "publish or perish", que define a hierarquia acadêmica e as recompensas correspondentes com base no sucesso em publicações especializadas, dominada por pesquisadores do meio universitário (DOSTALER et al., 2013). Isso cria um incentivo para que, em busca do sucesso acadêmico, os acadêmicos busquem divulgar seu trabalho em congressos e periódicos acadêmicos, pouco frequentados pelos praticantes (BAINES et al., 2009), o que reforça a linha editorial de revistas acadêmicas cada vez mais distantes do público praticante (REPSOLD et al., 2018).

Assim, sucedem-se coortes de professores do quadro de instituições acadêmicas por vezes alienados das práticas do campo, contribuindo para manter um padrão de ensino considerado pouco relevante para o mercado profissional (DOSTALER et al., 2013).

Embora o cenário pareça ser bastante negativo, há tanto acadêmicos quanto praticantes que acreditam e trabalham para que haja mais aproximação entre as duas comunidades, trazendo enormes benefícios mútuos, com forte impacto social positivo (BAINES et al., 2009). Por isso, é importante compreender de que forma se manifesta o distanciamento entre acadêmicos e praticantes, para que as barreiras sejam desfeitas (DIBB et al., 2009), e para que as perspectivas de cada grupo floresçam, fertilizandose mutuamente (MALHOTRA, 2018).

\section{Publicações em Livros e em Periódicos Acadêmicos de Marketing}

Praticantes de marketing precisam sempre estar atualizados porque sua área é muito dinâmica. É possível dizer, por exemplo, que os padrões de comportamento do consumidor mudam em pouco tempo, em função de pressões ambientais. Até poucos anos quase não se falava de digital, redes sociais, omnichannel, e hoje são tópicos que obrigatoriamente bons profissionais de Marketing são cobrados a dominar, por causa da expansão da internet e comércio eletrônico. Para se adequar às mudanças do mercado e à concorrência dinâmica, praticantes de Marketing buscam se manter informados, consultando livros, jornais, revistas e internet (REPSOLD et al., 2018).

No entanto, quando os praticantes normalmente citam livros que os inspiram em suas práticas de mercado, muitas vezes suas fontes não foram escritas por acadêmicos, ou, quando escritos por acadêmicos, são livros que possuem uma abordagem mais livre, mais orientada diretamente para a prática (REPSOLD et 
al., 2018), frequentemente baseadas em evidências anedóticas. Em geral, os praticantes se sentem confortáveis para utilizar algum modelo, teoria ou citação de livros que se consagraram ou estão nas tendências da moda como best-sellers, já que seus conceitos podem ser colocados em uma apresentação que consiga engajar a equipe para agir conforme desejado pelos apresentadores (BOURASSA et al., 2007).

Leigos podem se surpreender com o fato de que um artigo publicado em um journal bem qualificado pode gerar mais reputação para seu auto, do que um livro best-seller. Isso se dá em parte porque a produtividade dentro da comunidade científica é avaliada em maior parte pelas publicações e citações às mesmas, e, em maior grau, pelo sistema de avaliação de pares que garantem que os journals tenham uma responsabilidade muito maior em relação à qualidade e nível de evidência que seus artigos apresentam. Assim, enquanto os livros podem trazer para um autor notoriedade fora das fronteiras acadêmicas especializadas, é pela publicação de artigos científicos que a reputação no campo acadêmico é formada, em maior grau (CLEMENS et al., 1995).

Autores bem-sucedidos como Philip Kotler se tornaram amplamente influentes no campo por conseguirem didaticamente, via observações práticas e análises de casos, apresentar conceitos teóricos para um público amplo (BOURASSA et al., 2007). No entanto, pouco esforço se faz dentro da academia, principalmente brasileira, para que pesquisadores cruzem essa linha e traduzam o conhecimento científico para a comunidade (REPSOLD et al., 2017).

Nos Estados Unidos, porém, os livros são mais bem vistos pelos pares de instituições privadas e os artigos mais amplamente capazes de gerar reputação em instituições públicas (CLEMENS et al., 1995). Como no Brasil as instituições privadas muitas vezes remuneram seus professores somente pelas horas de trabalho em sala de aula e pouco incentivam a pesquisa e mesmo a extensão, temos um cenário em que o conhecimento acadêmico é em maior grau gerado por professores e pesquisadores das instituições públicas.

Nesse contexto, embora um artigo científico seja mais curto, mais específico e muitas vezes mais barato, é raro que executivos gastem tempo fazendo a leitura de tais artigos (SOUTHGATE, 2006), por desconhecerem ou rejeitarem os periódicos mais técnicos. Isso também reforça o distanciamento entre os profissionais e praticantes na área de Marketing. Umas das razões dos sucessos entre os profissionais de Marketing são a abordagem mais imediatista e concreta de questões práticas e o uso de linguagem mais fácil, quase jornalística, bem como a apresentação de modelos e técnica como receita de sucesso.

Para avaliar se as publicações de Marketing evidenciam esse suposto distanciamento entre teoria e prática, formulamos a seguinte hipótese:

$\mathrm{H}_{0}$ : Termos utilizados em títulos de livros e artigos científicos não diferem entre si em relação à proporção em que são usados.

\section{METODOLOGIA}

Buscando analisar o quanto os títulos de livros e artigos científicos são evidência do distanciamento entre praticantes do campo e acadêmicos, este artigo apresenta o resultado de uma pesquisa bibliométrica, que consiste na análise estatística de informações bibliográficas provenientes de livros, artigos e revistas 
(SANTOS et al., 2009). Tal esforço de pesquisa bibliométrica é importante para que, sob diversas perspectivas, possa se ter um panorama amplo sobre as publicações relacionadas à uma área ou tema e com isso se possa tomar decisões e ter melhor compreensão sobre a evolução e desenvolvimento de determinada disciplina (FISK et al., 1993).

Com intuito de buscar evidências do distanciamento de acadêmicos e praticantes por meio de títulos de livros e artigos científicos foi preciso fazer um recorte sobre quais dados seriam coletados e posteriormente analisados. Tais dados foram coletados utilizando a técnica de web-scraping por meio do software Octoparse.

Para a coleta de títulos de livros foi escolhida a base de dados secundária de livros em inglês disponíveis na Amazon.com, maior comércio eletrônico de livros do mundo, dentro dos seguintes tópicos: Consumer Behavior (351); e, Marketing Research (293). A escolha por esses tópicos se deu, pois, outros tópicos listados eram diretamente orientados para a prática, como, por exemplo, SEO ou Web Marketing. Foram coletados 644 títulos de livros publicados nos últimos 5 anos e disponíveis para venda na Amazon.com no formato de paperback e que tivessem ao menos 4 estrelas de avaliação, como forma de eliminar publicações de baixa qualidade e que não representassem o conteúdo mais aceito pela comunidade.

Para a coleta de títulos de artigos científicos foram escolhidos os três journals da área de Marketing mais bem ranqueados de acordo com o SCImago Journal \& Country Rank, desenvolvido a partir de informações da base Scopus, com intuito de avaliar o impacto, influência e prestígio dos journals científicos (SCIMAGO, 2020). Dessa forma, foram coletados os 920 títulos dos artigos publicados nos últimos 5 anos nas Journal of Marketing (252), Journal of Consumer Research (336) e Journal of Marketing Research (332).

Os dados foram analisados por meio da técnica de Análise de Conteúdo, que é o método adequado para sistematicamente descrever o significado de um material qualitativo (SCHREIER, 2012), de forma que inicialmente os termos utilizados nos títulos foram codificados em categorias criadas exaustivamente e, em seguida, procederam análises estatísticas. Por fim, com intuito de melhor compreender o quadro geral apontado pelos resultados estatísticos foi realizada uma análise posterior de interpretação na comparação de títulos com o mesmo conceito central.

\section{RESULTADOS}

\section{Análise de dados}

Para realização do Análise de Conteúdo foi utilizado o seguinte processo: a) enunciado do problema de pesquisa; b) seleção do material; c) construção do sistema de codificação; d) classificação do material em unidades de código; e) ciclos de depuração do sistema de códigos; f) análise dos dados; g) interpretação e apresentação dos resultados (SCHREIER, 2012).

A questão de pesquisa é se títulos de artigos científicos e livros evidenciam o distanciamento entre praticantes e acadêmicos, pois, conforme verificado na revisão bibliográfica, praticantes pouco se interessam em ler periódicos científicos. Foram coletados, dos 5 anos mais recentes, 1.564 títulos de artigos científicos, 
conforme a seguinte distribuição: Journal of Marketing (252), Journal of Consumer Research (336) e Journal of Marketing Research (332); e livros dos temas Consumer Behavior (351); e, Marketing Research (293), disponíveis na Amazon.com.

Para o processo de análise e codificação, os títulos foram divididos em unidades menores, a saber, os termos utilizados em cada um deles. Fez-se então um tratamento dos dados, eliminando conectores e artigos, que não representariam unidades de análises. A decisão por codificar e analisar por termos e não os títulos completos foi uma estratégia para supostamente reduzir a subjetividade do pesquisador na interpretação dos títulos (SCHREIER, 2012).

O sistema de codificação adotado foi misto (SCHREIER, 2012), isto é, a escolha de categorias emergiu dos títulos coletados e as categorias foram identificadas a partir do conhecimento prévio dos pesquisadores acerca da área de marketing. Foram feitas necessárias várias rodadas de análise para classificar o material e depurar a codificação, como forma de chegar em uma estratégia sólida de uso dos códigos.

Ao todo foram criados oito códigos, nos quais os termos foram classificados, são eles: Conceitos de Marketing: neste código foram classificados os termos referentes a uma construção teórica que possui significado compartilhado entre praticantes e acadêmicos. São exemplos de termos classificados neste código: marketing, valor, competitividade, lealdade, emoções; Objetos de Interesse na Área de Marketing: neste código foram classificados todos os elementos e atores palpáveis dentro do campo, que podem ser objetos de estudo e também alvos ou integrantes de ações mercadológicas. Exemplos: consumidor, cliente, profissionais, indústria, dados, dinheiro; Ferramentas da Administração de Marketing: termos referentes a instrumentos que possam ser utilizados por praticantes para elevar o desempenho de sua prática. Exemplos: mídia, digital, propaganda, planejamento, SEO; Instruções de Uso: termos que indicam a forma pela qual um determinado material (livro ou artigo) poderá ser utilizado ou a ação que ele pretende catalisar como desdobramento. Exemplos: guia, passo a passo, manual, construir, desenvolver, dominar; Qualificadores: termos qualificam determinado objeto, ferramenta ou finalidade. Exemplos: melhor, pior, menor, grande, bom; Ativos de Negócios: elementos que podem ser avaliados por seu valor financeiro. Exemplos: marca, concessão, prédio, produto, licença, patente; Mecanismos para Alcance da Finalidade: termos que representam algo necessário para que a finalidade da ação possa ser alcançada. São exemplos de termos classificados neste código: influenciar, persuadir, manipular, utilizar, compreender; Finalidade de Ações na Área de Marketing: termos relacionados aos objetivos finais que o Marketing pode ter enquanto prática. Exemplos: vendas, compra, gastos, uso, lucro.

Ao todo foram 5.112 termos codificados. A Tabela 1 é uma tabela de contingência $5 \times 8$, que apresenta como os termos se distribuíram em cada uma das fontes de dados utilizadas para as oito categorias de codificação.

Complementando as informações presentes na Tabela 1, a Tabela 2 é uma tabela de contingência 5 x 8 que apresenta os percentuais em que cada conceito representou do total de termos em determinada fonte de dados. 
Tabela 1: Distribuição de Termos Codificados por Fonte de Dados.

\begin{tabular}{|c|c|c|c|c|c|c|c|c|c|}
\hline & $\begin{array}{l}\tilde{O} \\
+\frac{ \pm}{U} \\
\text { U } \\
0 \\
0\end{array}$ & $\begin{array}{l}\stackrel{n}{0} \\
\stackrel{0}{0} \\
0 \\
0\end{array}$ & 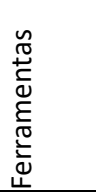 & 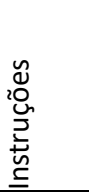 & 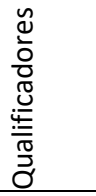 & $\stackrel{n}{\stackrel{n}{+}}$ & 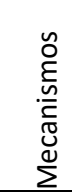 & $\begin{array}{l}\frac{0}{0} \\
\frac{\pi}{0} \\
\frac{\pi}{\sqrt{0}} \\
\stackrel{0}{\frac{\pi}{4}} \\
\end{array}$ & $\begin{array}{l}\bar{T} \\
\text { 음 }\end{array}$ \\
\hline Livros de Marketing Research & 223 & 129 & 278 & 133 & 66 & 117 & 17 & 57 & 1020 \\
\hline Livros de Consumer Behavior & 300 & 232 & 179 & 155 & 109 & 87 & 112 & 94 & 1268 \\
\hline Journal of Marketing Research & 450 & 170 & 164 & 9 & 32 & 72 & 38 & 86 & 1021 \\
\hline Journal of Consumer Research & 458 & 188 & 72 & 38 & 37 & 85 & 20 & 82 & 980 \\
\hline Journal of Marketing & 334 & 192 & 90 & 5 & 37 & 68 & 22 & 75 & 823 \\
\hline Total & 1765 & 911 & 783 & 340 & 281 & 429 & 209 & 394 & \\
\hline
\end{tabular}

Tabela 2: Percentual por Categoria por Fonte de Dados.

\begin{tabular}{|c|c|c|c|c|c|c|c|c|}
\hline & 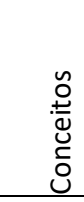 & $\begin{array}{l}\stackrel{n}{0} \\
\stackrel{0}{0} \\
0\end{array}$ & 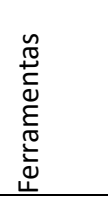 & 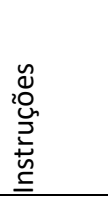 & 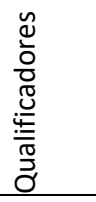 & 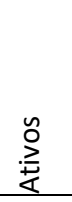 & 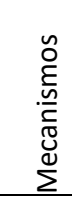 & $\begin{array}{l}\frac{0}{0} \\
\frac{\pi}{0} \\
\frac{0}{\sqrt{0}} \\
\frac{\mathbf{T}}{1} \\
\end{array}$ \\
\hline Livros de Marketing Research & $22 \%$ & $13 \%$ & $27 \%$ & $13 \%$ & $6 \%$ & $11 \%$ & $2 \%$ & $6 \%$ \\
\hline Livros de Consumer Behavior & $24 \%$ & $18 \%$ & $14 \%$ & $12 \%$ & $9 \%$ & $7 \%$ & $9 \%$ & $7 \%$ \\
\hline Journal of Marketing Research & $44 \%$ & $17 \%$ & $16 \%$ & $1 \%$ & $3 \%$ & $7 \%$ & $4 \%$ & $8 \%$ \\
\hline Journal of Consumer Research & $47 \%$ & $19 \%$ & $7 \%$ & $4 \%$ & $4 \%$ & $9 \%$ & $2 \%$ & $8 \%$ \\
\hline Journal of Marketing & $41 \%$ & $23 \%$ & $11 \%$ & $1 \%$ & $4 \%$ & $8 \%$ & $3 \%$ & $9 \%$ \\
\hline
\end{tabular}

Com intuito de verificar a $\mathrm{H}_{1}$, apresentada anteriormente, optou-se por agrupar os resultados das fontes que representam livros e separadamente das fontes que representam artigos. A Tabela 3 é uma tabela de contingência $2 \times 8$ que mostra o resultado dessa soma, assim como os percentuais de cada categoria em cada uma das unidades de análise.

Tabela 3: Distribuição e Percentual por Unidade de Análise.

\begin{tabular}{|c|c|c|c|c|c|c|c|c|c|}
\hline & 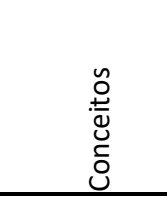 & $\begin{array}{l}\stackrel{n}{0} \\
\stackrel{0}{a} \\
0\end{array}$ & 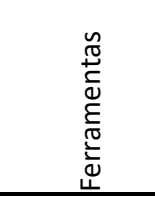 & 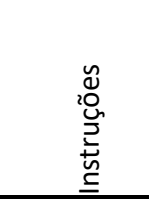 & 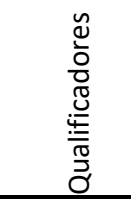 & 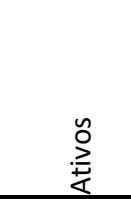 & 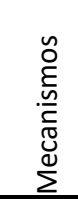 & $\begin{array}{l}\frac{0}{0} \\
\frac{\pi}{0} \\
\frac{0}{\pi} \\
\stackrel{0}{\frac{0}{4}} \\
\end{array}$ & $\begin{array}{l}\bar{\pi} \\
\stackrel{0}{0} \\
\end{array}$ \\
\hline Livros & 523 & & & & & & 129 & & \\
\hline \multirow{3}{*}{ Artigos } & $(23 \%)$ & 361 (16\%) & 457 (20\%) & $288(13 \%)$ & $175(8 \%)$ & 204 (9\%) & (6\%) & $151(7 \%)$ & 2288 \\
\hline & & & & 52 & & & 80 & & \\
\hline & $1242(44 \%)$ & 550 (19\%) & $326(12 \%)$ & $(2 \%)$ & $106(4 \%)$ & $225(8 \%)$ & $(3 \%)$ & $243(9 \%)$ & 1268 \\
\hline Total & 1765 & 911 & 783 & 340 & 281 & 429 & 209 & 394 & \\
\hline
\end{tabular}

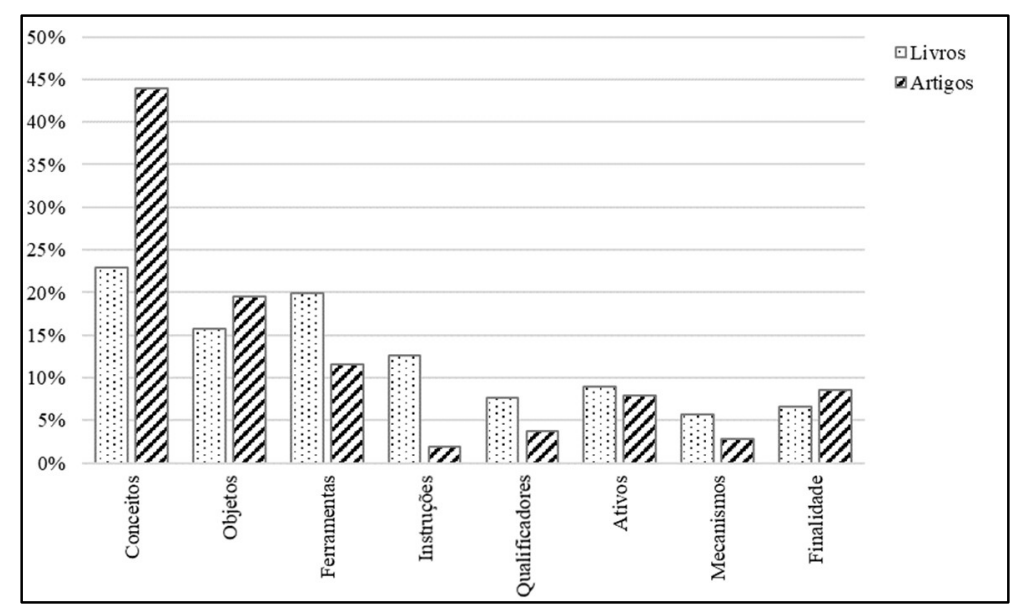

Gráfico 1: Percentual por Unidade de Análise.

O Gráfico 1 exibe as informações de percentual de utilização de cada código nos títulos de livros e 
artigos científicos para uma melhor comparação visual.

Com intuito de verificar a $\mathrm{H}_{1}$ o procedimento estatístico adequado foi a realização do Teste Quiquadrado de Pearson, que é utilizado para comparar dois varáveis categóricas (tipos de publicação (2); categorias de análise (8)) em que pelo menos uma dessa variáveis tenha três ou mais grupos (MAYERS, 2013).

A análise do Teste Qui-quadrado de Pearson $\left(\chi^{2}\right)$ indicou que existe uma associação significativa entre as categorias de análise (8) e o tipo de publicação (2), $\chi^{2}(7, N=5.112)=518,274, p=, 000, V$ de Cramer $=$ ,318 (indica a existência de associação entre as duas variáveis, em nível moderado).

Sendo assim, a partir do resultado do Teste Qui-quadrado podemos rejeitar a hipótese nula proposta, suportando a correspondente hipótese alternativa:

$\mathrm{H}_{1}$ : Termos utilizados em títulos de livros e artigos científicos diferem entre si em relação à proporção em que são usados.

Em seguida, foi possível observar os Resíduos Ajustados, que permitem verificar a fonte da associação significativa observada anteriormente. Para que dada categoria seja considerada como fonte da associação significativa é preciso que os Resíduos Ajustados sejam superiores à 1,96 (MAYERS, 2013). Os resultados para cada uma das categorias de código, com orientação para a categoria de artigos científicos, foram: Conceitos (15,8); Objetos (3,4); Ferramentas (-8,3); Instruções (-15,3); Qualificadores (-6,1); Ativos (1,2); Mecanismos (-5,0); e, Finalidade (-2,7). Assim sendo, apenas a categoria de Ativos não foi considerada como fonte da associação observada, o que implica que para esta categoria foi observada equivalência de frequência de distribuição esperada dos termos nas subamostras de títulos de artigos científicos e livros.

Com tais resultados do Teste Qui-quadrado de Person, V de Cramer e observação dos Resíduos Ajustados é possível seguirmos para a exploração e análise de algumas das categorias com resultados mais expressivos e da direção em que os resultados apontaram. Nos parágrafos seguintes, exploramos este ponto, trazendo alguns exemplos de pares de títulos de livros e artigos para ajudar a interpretar os resultados estatísticos.

A utilização de termos que remetem à categoria Conceitos representa a maior diferença entre livros e artigos científicos, sendo que em livros estes termos são utilizados com maior frequência. Em geral isso ocorre porque os artigos se encarregam de, muitas vezes, criar relações entre conceitos, criando um novo conhecimento a partir dessa relação. Um exemplo disso pode ser observado na diferença entre estes dois títulos: The Pizza Guide to Digital Marketing: A Delicious First Byte of the Biggest Business Game Changers of Your Lifetime (FARIOLI, 2019), título de livro em que apenas o conceito de Marketing está presente, de acordo com a categorização utilizada neste artigo; e, The Moderating Effect of Buying Impulsivity on the Dynamics of Unplanned Purchasing Motivations (SUHER et al., 2020), em que temos os conceitos de Impulsividade e Motivações sendo relacionados. A utilização de um número maior de conceito nos títulos dos artigos denota a maior profundidade na forma de tratar os temas da disciplina.

Os termos codificados como Instruções possuem a direção contrária dos Conceitos e, por sua vez, são mais frequentes em livros. Em geral isso está relacionado à necessidade de um livro se mostrar como uma fonte rápida ou completa para que o praticante possa implementar determinadas Ferramentas, 
categoria também mais frequente em livros. São exemplos de títulos de livros que usam Instruções associadas a Ferramentas: Keyword Research Like a Pro: The Ultimate Guide to Modren Keyword Research for SEO (CAPALA, 2019); e, Affiliate Marketing: Step By Step Blueprint to Earn A Six Figure Income on Autopilot from Anywhere in the World, Even if You Have No Experience (SPANNER, 2018). A utilização de Instruções com Qualificadores (por exemplo: ultimate) normalmente torna os títulos mais atraentes para potenciais compradores, ao mesmo tempo que mostra possível fragilidade na apresentação de conceitos sólidos e interrelações, provavelmente indicando que aquele conteúdo é mais superficial e muitas vezes voltado leigos que desejem alcançar resultados rápidos no campo. Esses exemplos, obviamente, são extremos na maneira como se apresentam, mas de maneira geral em nossa análise - e na constatação dos resultados científicos - o mercado de livros tem muito mais livros com tais características do que títulos mais comprometidos em realizar a tradução de conceitos técnicos importantes para os praticantes. Vale lembrar que, embora extremos, esses livros foram publicados em formato paperback, estão disponíveis na Amazon.com e, além disso, estão qualificados como acima de 4 estrelas de média, numa escala de um a cinco estrelas.

\section{DISCUSSÃO}

Este artigo visou responder ao questionamento se livros e artigos científicos são evidência do distanciamento entre praticantes da área de marketing e acadêmicos. Essa pergunta tem grande importância para qualquer disciplina profissional e aplicada. A análise de conteúdo de títulos de publicações de marketing evidenciou o distanciamento conjecturado. Essa evidência decorre da diferença em hábitos de leitura: praticantes são mais afeitos à leitura de livros técnicos ou obras mais gerais de marketing, ao passo que acadêmicos, estimulados pela socialização e pela estrutura do campo científico, estão acostumados a obter informações e atualização nos periódicos científicos, especialmente os mais qualificados, publicados em inglês e com alcance internacional (BAINES et al., 2009; CLEMENS et al., 1995; DOSTALER et al., 2013).

Foi possível verificar a partir da codificação dos termos dos títulos de publicações de marketing, análise dos dados e dos procedimentos estatísticos realizados, que a maior diferença entre livros e artigos científicos aparentemente está na apresentação de conceitos e no uso de instruções. Artigos científicos usam muito maior número de conceitos, porque muitas vezes mencionam relações entre eles e porque trabalham com problemas mais específicos com maior profundidade. Os livros, por outro lado, muitas vezes são mais focais, trabalhando somente um conceito com menor profundidade, e se valem de termos instrucionais para vender a ideia de facilidade de apreensão ou de acompanhamento durante o processo de adoção daquilo à que se propõem.

Refletindo sobre os resultados, podemos dizer que os artigos científicos em seu formato tradicional dificilmente terão apelo para praticantes do campo, se os títulos dos livros de fato representarem resposta àquilo que prioritariamente demanda o mercado. Essa análise coaduna com o pressuposto de que os praticantes buscam leituras mais diretamente aplicáveis em seu trabalho e que deem legitimidade à suas decisões aos olhos de colegas de trabalho (DIBB et al., 2009; KAUPPINEN-RÄISÄNEN et al., 2015; REPSOLD et al., 2018). 
No paradigma da ciência positivista há a crença de que artigos científicos não têm o papel de instruírem a prática diretamente, pois a função primordial da ciência seria descrever e explicar como as coisas são, em vez de normativamente indicar como deveriam ser. Há que se considerar, no entanto, a possibilidade de uma "ciência artística de Marketing", conforme propõe Veiga (2018), que seja capaz de reconhecer a importância da prática profissional, como base do aprendizado e experimentação criativa, a partir de uma perspectiva mais integrativa da ciência.

Ainda assim, apesar da divisão atual entre praticantes e acadêmicos, é possível ressaltar que existem muitos títulos de livros que são escritos por pesquisadores com carreira acadêmica de destaque, tais como Naresh Malhotra e Philip Kotler, autores de obras amplamente adotadas em cursos universitários, que usam linguagem atraente e agregam consistência teórica com inúmeras observações e casos práticos, tornando-se também muito apreciada pelos praticantes de marketing (BOURASSA et al., 2007). Por isso, é necessário que atores das duas militâncias profissionais façam a integração entre teoria e prática de Marketing, o que trará benefícios mútuos.

Atores do meio acadêmico devem cultivar o terceiro "braço" da Universidade, isto é a Extensão (os outros dois, a saber, são Ensino e Pesquisa). No caso do Brasil, em que a pesquisa é feita sobretudo em universidades públicas, esse incentivo à Extensão também depende de políticas e incentivos no âmbito governamental e legislativo. Por exemplo, com o Marco Legal da Ciência e Tecnologia os professores com dedicação exclusiva nas universidades passaram a poder atuar em projetos empresariais com uma carga horária limitada, o que contribui para que esta ponte seja pavimentada. Outra maneira de fomentar a Extensão seria deduções de impostos a empresas que investissem em projetos com universidades. Para isso, no entanto, é preciso vencer barreira no nível das unidades acadêmicas e departamentos que, muitas vezes, não valorizam no recrutamento de docentes e na sua avaliação de produtividade o intercâmbio com empresas e a realização de consultorias e projetos técnicos. Há, porém, sinais de que essa mentalidade pode estar mudando, haja vista que editais, como por exemplo a chamada Camp Serrapilheira 2020, do importante Instituto Serrapilheira (SERRAPILHEIRA, 2020), vêm prevendo recursos para projetos de divulgação científica, que ajudem a traduzir o conhecimento acadêmico para o público amplo, além de termos um aumento da valorização de atividades de extensão para fins de avaliação e classificação dos programas de pós-graduação pela Capes, com a inclusão do quesito Inserção Social (CAPES, 2019). Todas essas iniciativas mostram a tendência de do aumento do intercâmbio e cooperação entre praticantes e acadêmicos.

\section{CONCLUSÕES}

Em termos metodológicos este trabalho contribui para o corpo de pesquisas que empregam a Análise de Conteúdo para interpretar um grande volume de dados textuais obtidos na web.

Os achados do artigo mostram que a categorização utilizada para os termos se mostrou relevante na compreensão de enunciados na área de Marketing, ao passo que conseguiu explicar diferença nas frequências de subamostras, detectando um efeito moderado.

As implicações gerenciais são diferentes para públicos distintos. Profissionais de editoras de livros 
técnicos podem avaliar o potencial de aceitação de mais livros escritos por acadêmicos e como esses poderiam contribuir mais objetivamente para a prática profissional de marketing, levando em conta os pontos fracos e fortes possivelmente existentes em suas publicações. Publicações com características mais acadêmicas, usando linguagem acessível, podem atender uma demanda reprimida e ser um fator de diferenciação das editoras

Diretores de unidades acadêmicos públicas, coordenadores de curso de pós-graduação ou gestores em instituições particulares devem estimular projetos de extensão, para manter a disciplina de Marketing relevante para a comunidade profissional, evitando a imagem negativa de academia fechada em torre de marfim o que prejudica a atração de alunos com interesse na área.

O distanciamento verificado deve ser estímulo para que atores praticantes e acadêmicos superem seu isolamento, para que o marketing se fortaleça cada vez mais como disciplina científica e profissional. Mais intercâmbio deve favorecer a especialização e pressionar a academia a contribuir para solucionar os grandes problemas práticos de marketing enfrentados por profissionais, organizações e sociedade.

Para investigar evidências de distanciamento entre teoria e prática de marketing, este estudo aplicou a Análise de Conteúdo dos termos usados nos títulos de publicações da área, buscando reduzir a subjetividade de codificação. No entanto, sugerimos que estudos futuros adotem um sistema de codificação capaz de classificar os títulos in totum, interpretando a intenção subjacente dos autores, de forma a ampliar a percepção sobre as diferenças investigadas.

A pesquisa analisou obras publicadas em inglês, devido à facilidade de acesso à maioria dos títulos de livros técnicos de marketing via catálogos na Amazon.com. Ademais os principais periódicos acadêmicos de Marketing são publicados em língua inglesa. Entretanto, seria interessante ter uma visão exclusivamente brasileira sobre o tema de pesquisa, com base em publicações em português.

Outras pesquisas, qualitativas ou mistas, devem abordar as múltiplas percepções de praticantes e acadêmicos da distância entre teoria e prática de marketing, bem como das duas comunidades profissionais, coletando sugestões de como superar as barreiras, para que a ciência de marketing evolua a partir do estímulo da prática e a prática de marketing tire melhor proveito da ciência da área.

\section{REFERÊNCIAS}

BAINES, P.; BRENNAN, R.; GILL, M.; MORTIMORE, R.. Examining the academic/commercial divide in marketing research. European Journal of Marketing, v.43, p.12891299, 2009.

BOURASSA, M.; CUNNINGHAM, P.; HANDELMAN, J.. How Philip Kotler has helped to shape the field of marketing. European Business Review, v.19, p.174-192, 2007.

BRENNAN, R.. Should we worry about an "academicpractitioner divide" in marketing?. Marketing Intelligence \& Planning, v.22, p.492-500, 2004.

CAPALA, M.. Keyword Research like a Pro: The Ultimate Guide to Modren Keyword Research for SEO. 2019.
CAPES. Avaliação medirá impacto social e inserção regional das pesquisas. CAPES, 2019.

CLEMENS, E. S.; POWELL, W. W.; MCILWAINE, K.; OKAMOTO, D.. Careers in Print: Books, Journals, and Scholarly Reputations. American Journal of Sociology, v.101, n.2, p.433-494, 1995.

DIBB, S.; LYNDON, S.. Bridging the segmentation theory/practice divide. Journal of Marketing Management, v.25, n.3-4, p.219-225, 2009.

DOSTALER, I.; TOMBERLIN, J.. The great divide between business schools research and business practice. Canadian Journal of Higher Education, v.43, n.1, p.115-128, 2013. 
FARIOLI, C.. The pizza guide to digital marketing: a delicious first byte of the biggest business game changers of your lifetime. Dubai: Passionpreneur Publishing, 2019.

FISK, R. P.; BROWN, S. W.; BITNER, M. J.. Tracking the evolution of the services marketing literature. Journal of retailing, 69, n.1, p.61-103, 1993.

KAUPPINEN-RÄISÄNEN, H.; GRONROOS, C.. Are service marketing models really used in modern practice?. Journal of Service Management, v.26, 2015.

LIMA, M. P.; KRAEMER, F.; ROSSI, C. A. V.. A discussão epistemológica em marketing 1990-2010. Revista Brasileira de Marketing, v.13, n.1, p.133-143, 2014.

MALHOTRA, N. K.. Marketing research: current state and next steps. ReMark: Revista Brasileira de Marketing, v.17, p.18-41, 2018.

MAYERS, A.. Introduction to statistics and SPSS in psychology. Londres: Pearson Higher Education, 2013.

REPSOLD, F. C.; HEMAIS, M. W.. Distanciamento em marketing entre acadêmicos e praticantes. Brazilian Business Review, v.15, n.1, p.68-87, 2018.
SANTOS, R. N. M. D.; KOBASHI, N. Y.. Bibliometria, cientometria, infometria: conceitos e aplicações. Tendências da Pesquisa Brasileira em Ciência da Informação, v.2, n.1, p.155-172, 2009.

SCHREIER, M.. Qualitative content analysis in practice. Thousand Oaks: Sage publications, 2012.

SERRAPILHEIRA. Serrapilheira lança chamada pública de apoio a podcasts. 2020 .

SOUTHGATE, N.. The academic-practitioner divide: finding time to make a difference. Marketing Intelligence \& Planning, v.24, n.6, p.547-551, 2006.

SPANNER, M.. Affiliate marketing: Step-by-step blueprint to earn a six figure income on autopilot from anywhere in the world, even if you have no experience. Editora do autor, 2018.

SUHER, J.; HOYER, W. D.. The Moderating Effect of Buying Impulsivity on the Dynamics of Unplanned Purchasing Motivations. Journal of Marketing Research, v.57, n.3, p.548-564, 2020.

VEIGA, R. T.. Dialética da possibilidade de uma ciência artística de marketing. Curitiba: Appris, 2018.

A CBPC - Companhia Brasileira de Produção Científica (CNPJ: 11.221.422/0001-03) detém os direitos materiais desta publicação. Os direitos referem-se à publicação do trabalho em qualquer parte do mundo, incluindo os direitos às renovações, expansões e disseminações da contribuição, bem como outros direitos subsidiários. Todos os trabalhos publicados eletronicamente poderão posteriormente ser publicados em coletâneas impressas sob coordenação da Sustenere Publishing, da Companhia Brasileira de Produção Científica e seus parceiros autorizados. Os (as) autores (as) preservam os direitos autorais, mas não têm permissão para a publicação da contribuição em outro meio, impresso ou digital, em português ou em tradução. 